\title{
REPRESENTATIVE VOLUME OF DESIGN ELEMENTS AND MATHEMATICAL OF PILE WOVEN FABRICS
}

\author{
DR. ELSAYED AHMED ELNASHAR \\ Faculty of Specific Education \\ Kafer Elshekh, Tanta University
}

FACULTY OF SPECIFIC EDUCATION JOURNAL

NO. $9^{\text {TH }}$

JANUARY 2007 


\section{Representative Volume of Design Elements and Mathematical of Pile Woven Fabrics}

DR. ELSAYED AHMED ELNASHAR

Faculty of Specific Education

Kafer Elshekh, Tanta University

\section{ABSTRACT}

The paper presents an approach to model the behaviour of a representative volume design elements of pile warp woven fabrics. With the internal geometry of the built, the model computes overall parameters of the deformed pile warp woven fabrics, such as fibre volume fraction, porosity etc. The internal geometry is visualised and such properties as pore structure in typical cross-sections are analysed. The internal geometry description is further fed into flow modelling software, which allow computing local permeability and mechanical properties of the deformed the Loop of pile warp woven fabrics. This study aims at the structure of the geometrical characteristics of a warp pile woven fabrics structure by using the basic fabric parameters to find a suitable model that makes possible the prediction of weavability limited and suitable for their performance, and the evaluation of a three-dimensional plain pile warp woven fabrics geometrical model. Dimensional plain pile warp woven fabrics geometrical model. Loop lengths, realistic models based on a better approach of geometry and material properties will be created in order to investigate the numerical analysis performance of the performance properties of pile warp woven fabrics. Porosity, air permeability of a woven fabric on the base of its constructional parameters. Of the warp pile woven fabrics structure via module. As the constructional parameters of a woven fabric are considered: maximum and suitable setts of warp and weft yarns, diameters (or fineness) of warp and weft yarns and a type of weave. This research is focused on cloth warp pile woven fabrics structure of warp cotton and several types of weft. The evaluations of the geometrical model for three level of loop length (height, medium, low) are carried out by three methods of weft density. based on the comparison of the measured warp pile loop length of existing warp pile woven fabrics structure fabrics with the calculated values that result from the geometrical model. And controlled of the shape of the warp pile loop that result from the air permeability, thickness, porosity, test of the fabrics with the air permeability, thickness, porosity curves that are received from the simulation of the analysis. A correlation between calculated values of structural parameters and experimental; The suggested process makes possible prediction of ideal sett of weft for terry woven fabric in three densities (18) wefts with the rest of possible properties throw porosity and value of air permeability, wick-up of 
pile warp woven fabrics, to the materials types of weft which are: cotton, polyester, blended (cotton/polyester (50/50)) viscose rayon, which are characterised by their constructional parameters as are sett of piles warp and ground yarns, by diameters or fineness of cotton materials and by the plain of weave

Keywords: weavability limited, geometrical pile fabric, permeability, porosity. geometrical Models,

\section{INTRODUCTION}

The continuously increasing demand of the consumers, the rapid change of the style and material of the end products, the competitiveness of the market in the textile industry and its globalisation are imposing imperatively the need of optimization in the relation of fabric quality and cost production. Since today, the fabric production is based on experience, intuition and the logic of the trial and error. This procedure delays significantly the production of the desirable pile warp fabric, increasing its cost, provided that it includes repeated production of pile warp samples, test of their properties, comparison with the desirable properties and change of the initial parameters until the achievement of the desirable sample. The repeated modification in the pile warp fabric design procedure introduces the problem of the prediction a suitable of the fabric properties before its production in order to reduce the design period duration (Hearle, 2004).[10]. The prediction a suitable of the mechanical behavior of pile warp fabrics using analytical methods is restricted by the complexity of the fabric structures, the anisotropic properties of the yarns, their high deferability and also the contact phenomena. For these reasons the use of FEA(Finite Elements Analysis) becomes continuously wider for the modelling of suitable fabrics' structures. The modelling, of course, requires the knowledge of mechanical properties of the yarn and a suitable the geometrical characteristics of the fabric. Several studies have been carried out to analyze the dimensional properties of woven fabrics structures with prevailing these from Chamberlain(1926), Peirce (1947), [3, 14].these studies have presented either formulated geometrical models consisting of known curves, for example circular arcs and straight lines, or the results of measurements that have been carried out on a series of a suitable pile warp woven fabrics structures. A recent extended research work presents the 3D modeling based on elastic theory. The problem with the existing geometrical models of pile warp woven fabrics structures is in some cases the insufficient accuracy of the predicted dimensions or their difficulty to be used for the generation of the 3-dimentional representation of the structure (Vassiliadis et al, 2005)[19]. The present work focuses on the estimation of the geometrical characteristics of a of a warp pile 
woven fabrics structure fabric structure supporting the maximum, and suitable possible accuracy in order to ensure the numerical modeling success by using FEA with a special stress on contact analysis. The maximum number of ends picks per unit length that can be woven with given yarn and weave is an important issue for weave designers, weaving designer should be sufficiently familiar with construction limit to avoid difficult and unachievable constructions. With constructions above or near the upper weavability limit, parts of weaving machine may be over stressed and damaged. For this reasons, The Empirical and Theoretical Relationships(ETR)relating maximum warp and filling cover factors regular yarns have been derived to theoretical relationships are provided in graphic forms for simple weaves [17] [4]. Plate et el recommended using a full-width temple and early shed for weaving tight fabrics [15]. Seyam et al[17] studied the weavability limit of fabrics mad from irregular thickness filling yarn. They conclude that yarn regularity increases weavability limit. Seyam, et el[16]. Also concluded that weavability limit depends on warp and weft yarn counts, fiber packing in the yarn(spinning method), fiber type, weave design (warp and filling spacing), loom type and setting, and yarn uniformity. Snowden [18] states that limits of setts depend on loom construction and weaving condition. That weavability limit depends. These limits depend on loom(light or heavy), Dobby mechanism(negative or positive), let-off mechanism, and take-up mechanism. Weaving condition that affect limits of setts are warp tension, shed change timing and back rest position.

The object of this work: foundation and the suggested process makes possible Mathematical of pile woven fabrics to prediction of suitable sett of warp and weft, porosity and air permeability value of pile warp woven fabrics(cotton), which are characterised by their constructional parameters as are sett of warp and weft yarns, diameters or fineness of warp and weft yarns and by the plain of weave.

On the base of the area covering value is chosen suitable model for description of woven fabric structure.

Three variants of cumulative parameter of a pile warp woven fabric structure were introduced.

The realistic models based on a better approach of geometry and material properties will be created in order to investigate the numerical analysis performance of the mechanical properties of warp pile woven fabrics: -to determine the weavability limit and suitable as a function of warp pile weave design and yarn diameters, and to give an idea about the maximum crimp ratio of warp pile weave and cover ratio of fabrics, the lower value of weavability limit and suitable are more achievable than the higher value especially on 
modern sand faster weaving machines rather than multi-phase weaving machine.

This research is focused on cloth of pile warp woven fabrics of a cotton type. Two variants of so-called cumulative parameter of a woven fabric structure are defined and they are applied on the set of woven fabrics. A correlation between calculated values of structural parameters and experimental air permeability values was evaluated. A structure of textile materials is very complicated and very varied. Therefore it is reasonable to use various models of a textile structure for the various groups of the textiles. The group of the textiles can be characteristic for example by some structural parameter(s).

\section{Maximum construction theories [18]}

Ashenhurst's "ends plus intersections" theory: this theory states that

$$
t_{1}=\frac{e}{d(e+i)}=
$$

$\mathrm{t}=$ max. ends or picks/inch, $\mathrm{e}=$ ends or picks/weave repeat, $\mathrm{i}=$ intersection/ weave repeat , $\mathrm{d}=$ yarn diameter in inches

A) Weave angle [4]

$$
\begin{aligned}
& \cos \varnothing_{1}=\frac{d_{1}}{d_{1}+d_{2}}= \\
& \cos \varnothing_{2}=\frac{d_{2}}{d_{1}+d_{2}}= \\
& \cos \varnothing_{1}+\cos \varnothing_{2}=1
\end{aligned}
$$

$\mathrm{d}$ is yarn diameter.

b) Yarn spacing (P)

$$
\mathrm{P}_{1}=\sqrt{d_{1}^{2}+2 d_{1} d_{2}} \quad \mathrm{P}_{2}=\sqrt{d_{2}^{2}+2 d_{1} d_{2}}
$$

\section{C) Yarn crimp ratio (C) [4]}

$$
\begin{gathered}
\left.c_{1}=\frac{\frac{\pi}{180}\left(d_{1}+d_{2}\right) \cos ^{-1} \frac{d_{1}}{d_{1}+d_{2}}+\left(F_{1}+1\right) d_{2}}{\sqrt{d_{2}^{2}+2 d_{1} d_{2}+\left(F_{1}+1\right) d_{2}}}-1\right] \\
\left.c_{2}=\frac{\frac{\pi}{180}\left(d_{1}+d_{2}\right) \cos ^{-1} \frac{d_{1}}{d_{1}+d_{2}}+\left(F_{1}+1\right) d_{2}}{\sqrt{d_{1}^{2}+2 d_{1} d_{2}+\left(F_{1}+1\right) d_{2}}}-1\right]
\end{gathered}
$$


Yarns cover Ratio (K)[4]

$$
\begin{aligned}
& K_{1}=\frac{d_{1}}{\sqrt{d_{2}{ }^{2}+2 d_{1} d_{2}}} \\
& d_{2}=\frac{d_{2}}{\sqrt{d_{2}{ }^{2}+2 d_{1} d_{2}}}
\end{aligned}
$$

e) Cloth cover Ratio (Kc)[5]

$$
\begin{aligned}
& K_{c}=\frac{d_{1}}{\sqrt{d_{1}^{2}+2 d_{1} d_{2}}}+\frac{d_{2}}{\sqrt{d_{2}^{2}+2 d_{1} d_{2}}} \\
& \sqrt{2 d_{1}^{3} d_{2}+5 d_{1}^{2} d_{2}^{2}+2 d_{1} d_{2}^{3}}
\end{aligned}
$$

f) Maximum Sett (n)[4]

$$
\begin{aligned}
& K_{1}=\frac{F_{2} d_{1}}{\sqrt{d_{1}{ }^{2}+2 d_{1} d_{2}+\left(F_{2}-1\right) d_{1}}} \\
& K_{2}=\frac{F_{1} d_{2}}{\sqrt{d_{2}{ }^{2}+2 d_{1} d_{2}+\left(F_{2}-1\right) d_{2}}}
\end{aligned}
$$

\subsection{POROSITY OF WOVEN FABRIC}

All of the methods, which lead to determination or expression of a textile material porosity, include some simplifying assumptions. These assumptions introduce into result some inaccuracies. It is very difficult to find the optimal method that the most predicates about of textile properties such as for example air permeability of textile. Classical 2-dimensional model of porosity In theory of classical 2-D model, porosity PS [10] is defined as:

$$
P_{S}=1-\left(d_{O} D_{O}+d_{U} D_{U}-d_{O} D_{O} d_{U} D_{U}\right)
$$

where $d_{O}, d u$ are diameters of a warp yarn, weft yarn respectively, and $D_{O}, D_{U}$ are setts of warp yarns, weft yarns respectively. This model of porosity completely neglects the third dimension of a fabric and neglects the differences of pore forms due to various weave types.

\section{* Modified 2-dimensional model of porosity}

This model suggested by Gooijer (Gooijer, 1998) [6(Marie Havrdova [8] includes partly a3-D structure of pores. A various binding type does not show the same relationship between a projected and real effective area opened to a flow. The modified 2-Dmodel of porosity is based on idea that air flows around of yarns not only in a perpendicular direction. The influence of the binding was described with four basic unit cells according to Backer(Backer, 1951).[2]Each type of a woven fabric can be described by using 4 pore types showed on fig 1 . 


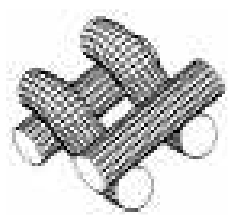

Pore type 3

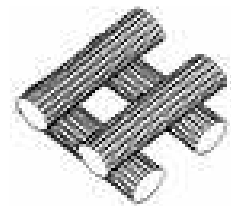

Pore type 4

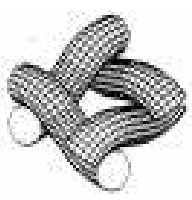

Pore type 1

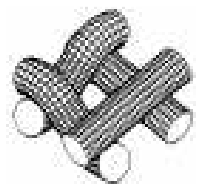

Pore type 2

Figure (1):

the unit cells for woven fabric

(Backer, 1951)

Gooijer [6] calculated a projection of a wetted perimeter at the narrowest cross section of a pore of four yarns creating of a pore into plane of a fabric and derived four equations for a calculation of the effective open areas A1 - A4 of pore types $1-4$. The final equations have the form:

$$
\begin{aligned}
& A_{1}=A_{O} A_{U}-\frac{\pi}{4} d_{U}\left(A_{O}-\frac{d_{O}}{2}\right)-\frac{\pi}{4} d_{O}\left(A_{U}-\frac{d_{U}}{2}\right) \\
& A_{2}=A_{O} A_{U}-\frac{\pi}{8} d_{U}\left(A_{O}-\frac{d_{O}}{2}\right)-\frac{\pi}{8} d_{O}\left(A_{U}-\frac{d_{U}}{2}\right)-\frac{d_{O}}{2} A_{U} \\
& A_{3}=A_{O} A_{U}-\frac{d_{O}}{2} A_{U}-\frac{\pi}{4} d_{U}\left(A_{O}-\frac{d_{O}}{2}\right) \\
& A_{4}=A_{O} A_{U}-A_{U} d_{O}
\end{aligned}
$$

Here $A_{O}, A_{U}$ are distances between warp and weft yarns (the reciprocal value to sett of yarns $\left.D_{O}, D_{U}\right)$. Now, the porosity $P_{G}$ can be calculated for each type of weave:

$$
P_{G}=\frac{p_{1} A_{1}+p_{2} A_{2}+p_{3} A_{3}+p_{4} A_{4}}{\frac{n_{S O} n_{S U}}{D_{O} D_{U}}}
$$

where: $p_{1}-p_{4}$ are numbers of pores (type $1-4$ ) in pattern repeat and $n_{S O}$, $\mathrm{n}_{\mathrm{SU}}$ are numbers of binding points in pattern repeat in warp and weft direction. So-called cumulative parameter of a woven fabric structure $S_{T}$ was proposed in the form (in detail see the work (Havrdová, 2003))[2]:

$$
S_{T}=P_{S} f^{u}
$$

where $\mathrm{P}_{\mathrm{S}}$ is porosity of a woven fabric calculated according to the equation(2). The parameter $f[10]$ is a degree of interlacing of yarns in a woven fabric and it describes the relative passage of weft yarns between the right side and underside: 


$$
f=\frac{1}{\frac{z_{U}}{n_{S O} n_{S U}}}
$$

where $\mathrm{Z}_{U}$ [2] is a number of passages of weft yarns between the right side and underside, $\mathrm{n}_{\mathrm{SO}}$ and $\mathrm{n}_{\mathrm{SU}}$ are a numbers of warp and weft yarns in a pattern repeat respectively. The parameter $u$ [2] in equation (8) is a relative shift of neighbouring weft yarns. It was proposed in work (Havrdová, 2003) [9]for elementary types of weave in the form:

$$
u=\frac{n_{p o s}}{n_{S O}}
$$

where $n_{\text {pos }}$ [2] is a number of binding points about which are shifted the neighbouring weft yarns each other. In a second variant, in the equation (8) is exchanged parameter $\mathrm{u}$ with parameter $\mathrm{m}$. $\mathrm{m}$ is so called weaving exponent suggested by Brierley. This parameter describes a chance of pushing one yarn under second yarn in the free weave types. Then is the suggested cumulative parameter in the form:

$$
S_{T}=P_{S} f^{m}
$$

A numbers of anothers porosity models were introduced (for example Pedersen (Pedersen, 1974)[13], Lu (Lu et all, 1996)[12] or Höerner (Höerner, 1952)[2], but in these models the influence of a weave type on the woven fabric air permeability is not enough regarded. Most authors regard the shape difference between individual types of pore units (as were defined by Backer (Backer, 1951))[2]. but not regard their mutual arrangement. The arrangement each other of the four pore types crates a weave of a fabric.

\section{Volume porosity model:}

This model suggested by(Elnashar, 2005) [5] includes partly a 3-D structure of pores. A various binding type does not show the same relationship between a projected and real effective area opened to a flow. The modified 2-D model of porosity is based on idea that air flows around of yarns not only in a perpendicular direction. the flowing equation (22).

$$
\begin{aligned}
& R v=\frac{1000 \pi\left(2 d_{P I} d_{P I B} d_{P I r} T_{P I} \gamma_{P I} 4 T_{T K}\right) \varpi / 2}{T_{T K} T_{P I} \gamma_{P I} \sqrt{\left(1-0.01 a_{P I}\right) 100}} \\
& +\frac{P_{G}\left(1000 \pi d_{G B} d_{G r} \gamma_{P I} 4 T_{G}\right.}{T_{T K} T_{G} \gamma_{G}\left(1-0.01 a_{G}\right) 100} \\
& \times \frac{1}{\sqrt{\frac{P_{y}\left(1000 \pi d_{y B} d_{y r} d_{P I B} \gamma_{y} 4 T_{y}\right)}{4 T_{T K} \gamma\left(1-0.01 a_{o}\right) 100}}} \times \frac{1}{I_{f C}}
\end{aligned}
$$


Here, the first factor represents. Then; volume porosity is given by these samples Symbols description for equation: Where: $R v=$ volume porosity,$T_{T K}=$ thickness of warp pile woven fabrics. TPI; $\boldsymbol{T}_{G}$; yarn count of pile and ground warp in Tex system. $\boldsymbol{T} y$; Yarn count of weft in Tex system. $a_{P I} ; a_{G}$; crimp for pileand ground warp, $a_{y}$; crimp for weft. $P P I$; $P_{G}$; density of yarns/cm for pile warp and ground warp. $P_{y}$; density of yarns/cm for weft. $\gamma_{P I ;}, \gamma G$; scientific density for pile and ground warp spun fibers. $\gamma_{\mathrm{y}}$; scientific density for weft spun fibers. $d_{P I B}$; vertical cross section for yarn warp. $d_{G B}$; Vertical cross section for pile and ground warp. $d_{y B}$; vertical cross section for yarn weft. $d_{P I r}$; $d_{G r}$; horizontal cross section for pile and ground warp. $d y r$; horizontal cross section for weft yarn. $L_{P I o} ; L_{R}$; length yarn of pile and ground warp extended between tow intersections in perfect repeat of woven construction. $L_{y_{R} ;}$; Length of weft yarn extended between tow intersection in perfect repeat of woven construction. $L_{P I o} ; L_{R G}$; width repeat of pile and ground warp. $\varpi$;Number of piles in cmm. $L R_{y}$;width of repeat of weft. $R$ PIo; $R G$ ;number of yarn repeats for pile and ground warp. $\mathrm{R}_{\mathrm{y}}$; number of yarn repeats for weft. $a_{P I o}$; $a_{G}$; crimp for pile and ground warp. $a_{y}$; crimp for weft. $P_{P I ;} P_{G}$; density of yarns/cm of pile and ground warp. $P_{y}$; density of yarns $/ \mathrm{cm}$ of weft. And $I F C=1$.So, $\gamma$ : Scientific density for cotton(1.54)-viscose(1.46)polyester(1.38).-Fibran (1.52) and the blended (cotton/polyester (50/50) (1.46) the length of yarn (ground warp-weft) in equation (4A, B), first the length of warp extend between two intersection in perfect repeat of woven construction. (LGR).

\section{Experimental Materials and Method}

\subsection{Materials:}

Experiments were carried out on warp pile woven fabrics, which were constructed according to the setting theory. The used are carded warp yarns of 50 Tex for warp pile, 50 Tex for ground warp, was spun from 100\% cotton staple fiber and weft variables are presented in Table (1). Experiments are carried out on Three levels group of pile fabrics structure( higher loop, medium and low loop). Experiments packing are carried out on Three densities group of weft structure $(15,18,21) \mathrm{per} / \mathrm{cmm}$. The factor and the factor of thread flexibility are determined according to the values given in the literature. The parameters of woven fabric structure are the weave factor and fabric leaner density of weft. All variables used in determining the weave factor are collected. The values for maximum leaner densities, setting thread density; A group of samples made 
weft from polyester, fibran, viscose, blended (cotton/polyester(50/50)), and cotton. The pile warp woven fabrics samples are The fabrics designed formation technique and produced on the Picanol weaving machine attachment with head of jacard in Eldelta spinning and weaving-Tanta and (Zifta factory) company-Egypt, and The fabrics tested in consolidation fund at Alexandria., faculty of science, Tanta university, and faculty of engineering Elmansura university, According to A.S.T.M, standards,[1]

Table (1): Describe of fabric specification

\begin{tabular}{|l|l|l||}
\hline Warp threads & Loop & Ground \\
\hline \hline & cotton & cotton \\
\hline Materials & 50 Tex & 50 Tex \\
\hline Leaner density & \multicolumn{2}{||}{} \\
\hline \hline Density/cmm & 11 & 11 \\
\hline \hline A & 11 & 11 \\
\hline B & 11 & 11 \\
\hline C & & \\
\hline \hline Wefts & $37.5 \mathrm{Tex}$ & \\
\hline \hline cotton & $40 \mathrm{Tex}$ & \\
\hline viscose & $25 \mathrm{Tex}$ & \\
\hline blended & $17 \mathrm{Tex}$ & \\
\hline polyester &
\end{tabular}

Used Plain weave, denting in one gate: 1 pile warp yarns in First face , 1 pile warp yarns in second face, 2 ground yarns.

\subsection{Experimental methods:}

2.3.Permeability Testing of textile materials is possible to characterise as their ability to transmit air under given conditions.Under laboratory conditions the air permeability is standard evaluated according to EN ISO 9237, in faculty of engineering Elmansura university,.Egypt.According to ASTM for Testing and Material [1].

\subsection{CALCULATE THE DIAMETERS OF THREADS AND WEIGHT}

d1 upper face \&d1 lower face of warp piles as indicated of(Grosbarg)[7].In the following equation: $\mathrm{d}=4.44\left(\sqrt{ }\right.$ Texcount/fiber density) $10^{-}$ ${ }^{3} \mathrm{~cm}$. ....(23)[7]

$\mathrm{dPI}=4.44(\sqrt{50} / 1.54) 10^{-3}=0.02038 \mathrm{~cm}$.

Where:dPI=diameter of warp piles cross section. To find the(weight)of 
pile warp by the following equation: $W=\pi\left(d^{2} / 4\right) L^{*}$ number of pile threads in cloth ....(24)

$$
=3.14(0.02038 * 0.02038 / 4) * 366 * 71.5 * 3=25.59 \text { gram }
$$

To find the diameter of warp ground cross section,(dg)as indicated of Grosbarg the following equation: $\mathrm{d}=4.44(\sqrt{ }$ Tex count $/$ fiber density $) 10^{-3} \mathrm{~cm}$.

$$
\mathrm{dg}=4.44(\sqrt{50} / 1.54) 10^{-3}=0.02038 \mathrm{~cm} \text {. }
$$

Where: $\mathrm{dg}=$ diameter of warp ground cross section.

To find the weight of warp ground by the following equation: $W=\pi\left(d^{2}\right.$ /4) $\mathrm{L}^{*}$ number of warp ground threads in cloth

$$
=3.14(0.02038 * 0.02038 / 4) * 366(30 * 10.8)=3.86 \text { gram }
$$

\subsection{RESULT AND DISCUSSION}

\subsubsection{CALCULATE POROSITY \%:}

This equation gives us more fitting results, it attention in calculate the volume porosity and inner porosity, especially when use the Pile warp woven cloth in Toweling or garments. This model was constructed to have a geometry complicated enough to see the effect of changing the medium location but simple enough to save computational time. Due to geometric symmetry, only one-quarter of the perform was modeled. Four different high-permeable medium locations were examined. The permeability of the Seaman highpermeable distribution medium was used in the simulations as the following calculate the Pile warp woven fabrics porosity construction \% in regular Reed dents system with plain weave for warp pile woven fabrics by using the equation(22).

\subsubsection{BASIC OF THE GEOMETRICAL PILE WOVEN FABRIC MODEL}

Basic parameters of a pile woven fabric are: loop width $\Omega r$, loop height $\Delta r$, loop length $\ell$ pi, $\quad \ell p i=\pi \Delta r-\Omega r$

Where $\ell$ is loop length [mm], $\Omega r$ is loop width [mm], $\Delta r$ is loop height $[\mathrm{mm}]$

$$
\begin{aligned}
& p_{1}=2 d p_{i}+d_{2} \\
& p=4 d p_{i}+3 d_{2}
\end{aligned}
$$

Where: $\mathrm{p} 1$, space between wefts of loop fasted 
$P:$ Widths repeat. And $d p_{i}$ : is pile yarn thickness[mm]. The loop length is influenced by the yarn input tension, pile woven fabric take-down tension, pile woven velocity, materials friction in the pile woven zone, yarn structure and properties, yarn linear density, etc. The pile woven fabric vertical density $\mathrm{W}$ :is defined by the pile woven density and the yarn input tension; it changes only slightly with the change of the yarn input tension for conventional yarns for elasticized. The vertical density of the pile woven fabric changes with depth change. The loop length increases and simultaneously the vertical density is reduced. The materials relaxation process usually comprises shrinking of the pile woven fabric.Dry relaxation begins immediately after exiting the pile woven zone when the tension applied to the loops during the pile woven process is reduced. The relaxation takes some time, depending on the yarn material composition, the horizontal/vertical density and the structure of the pile woven fabric, and loads applied to the fabric prior to relaxation. The portion of the immediate shrinkage natural materials Pile woven fabric is wet relaxed during wet after-treatment processes like bleaching and dyeing and additionally during the care process,e.g. laundering and steaming. Theoretically, a pile woven fabric changes continually and perpetually tends to attain more stable state than the previous one. The changes are also influenced by the factors like temperature, relative humidity, pressure of materials etc. As the changes are not visible anymore the state is comply with the order. The relaxation shrinking can easily be monitored through the changes of the vertical and horizontal density and the mass per unit area repeated -Three variants of cumulative parameter of a pile warp woven fabric structure were introduced. considered to be balanced. The determination of the shrinking is very important when planning the materials quantity of the fabric to be pile woven to The main structural parameters of a warp pile woven fabrics fabric are: the head of loopspacing (P): Widths repeat. the The pile woven fabric vertical density (w) and the thickness of the pile yarn $\left(d p_{i}\right)$. The rest of the geometrical parameters required for the complete description of the structure derive analytically from them. The estimation of the geometrical parameters has been based on the assumption of the ideal cotton yarn of towel fabrics. Thus the yarns are represented as homogenous cylinders of constant diameter for pile and ground, with initial restricted contact area between them. We consider initially the independent parameters $\mathrm{c}, \mathrm{W}, \mathrm{d} 1=\mathrm{d} 2=d p_{i},, P 2, P 1, P$, and in addition the: distance $t$ as it is noticed in figure (2)A,B,C Geometrical model of Low level of warp pile woven fabrics structure . 

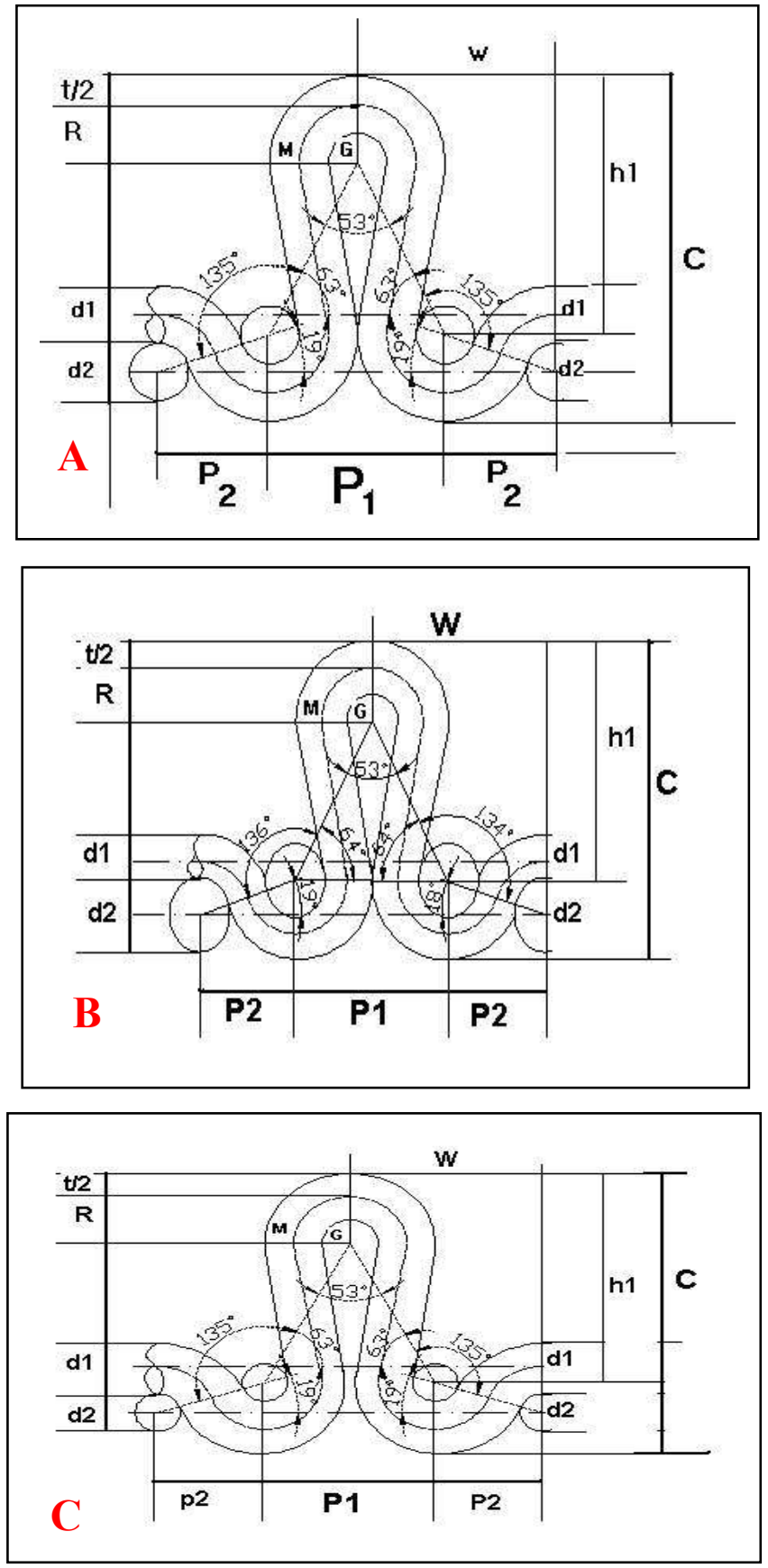

Figure 2, A,B,C Geometrical model of Low level of warp pile woven fabrics structure. 
Table 2 Comparison of measured of level the warp pile loop length.

\begin{tabular}{|c|c|c|c|c|c|c|c|c|c|c|c|}
\hline \multirow{2}{*}{$\begin{array}{l}\text { Weft } \\
\text { Type of } \\
\text { yarns }\end{array}$} & \multirow{2}{*}{ 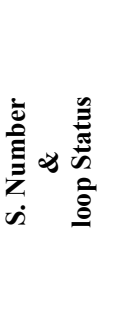 } & \multirow{2}{*}{ 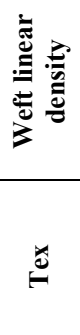 } & \multirow{2}{*}{ 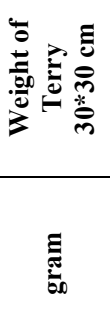 } & \multirow{2}{*}{ 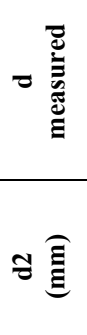 } & \multicolumn{3}{|c|}{ Pile measured } & \multirow{2}{*}{ 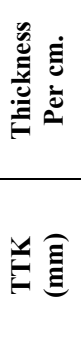 } & \multirow{2}{*}{ 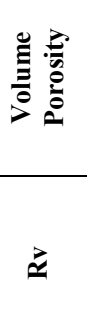 } & \multirow{2}{*}{ 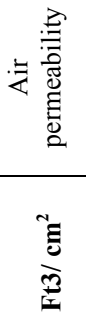 } & \multirow{2}{*}{ 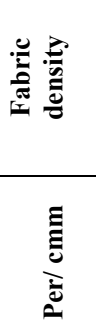 } \\
\hline & & & & & 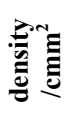 & 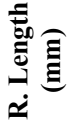 & $a$ & & & & \\
\hline $\begin{array}{c}\text { Cotton } \\
\text { Density A }\end{array}$ & 25-Low & 37.5 & 17.8 & 0.017 & 37.5 & 0.37 & 0.134 & 3.2 & 30.7 & 31.8 & $22 \times 21$ \\
\hline $\begin{array}{c}\text { Cotton } \\
\text { Density B }\end{array}$ & 36- Low & 37.5 & 17.09 & 0.017 & 32.5 & 0.43 & 0.134 & 3.25 & 27.5 & 32.0 & $22 \times 18$ \\
\hline $\begin{array}{c}\text { Cotton } \\
\text { Density C }\end{array}$ & 31- Low & 37.5 & 16.37 & 0.017 & 30 & 0.47 & 0.134 & 3.5 & 22.65 & 32.0 & $22 \times 15$ \\
\hline $\begin{array}{c}\text { Viscose } \\
\text { Density A }\end{array}$ & 26 Low & 40 & 18.28 & 0.018 & 37.5 & 0.37 & 0.155 & 2.45 & 36.6 & 31.7 & $22 \times 21$ \\
\hline $\begin{array}{c}\text { Viscose } \\
\text { Density B }\end{array}$ & 33- Low & 40 & 17.50 & 0.018 & 32.5 & 0.43 & 0.155 & 3.0 & 33.85 & 31.9 & $22 \times 18$ \\
\hline $\begin{array}{c}\text { Viscose } \\
\text { Density C }\end{array}$ & 32- Low & 40 & 16.72 & 0.018 & 32.5 & 0.43 & 0.155 & 3.4 & 26.85 & 31.9 & $22 \times 15$ \\
\hline $\begin{array}{c}\text { blended } \\
\text { Density A }\end{array}$ & 28- Low & 25 & 16.51 & 0.015 & 37.5 & 0.37 & 0.142 & 3.15 & 21.19 & 32 & $22 \times 21$ \\
\hline $\begin{array}{c}\text { blended } \\
\text { Density B }\end{array}$ & 35- Low & 25 & 15.98 & 0.015 & 32.5 & 0.43 & 0.142 & 3.4 & 16.38 & 32 & $22 \times 18$ \\
\hline $\begin{array}{c}\text { blended } \\
\text { Density C }\end{array}$ & 29- Low & 25 & 15.45 & 0.015 & 30 & 0.47 & 0.142 & 3.7 & 31 & 32 & $22 \times 15$ \\
\hline $\begin{array}{l}\text { polyester } \\
\text { Density A }\end{array}$ & 27- Low & 17 & 15.92 & 0.014 & 37.5 & 0.37 & 0.138 & 3.9 & 13.53 & 31.7 & $22 \times 21$ \\
\hline Density B & 34- Low & 17 & 15.8 & 0.014 & 32.5 & 0.43 & 0.138 & 3.6 & 14.14 & 31.9 & $22 \times 18$ \\
\hline Density C & 30- Low & 17 & 15.32 & 0.014 & 30 & 0.47 & 0.138 & 3.45 & 24.29 & 31.9 & $22 \times 15$ \\
\hline
\end{tabular}

**Cotton Density A : it means the picks $21 / \mathrm{cmm}$ wefts ,Cotton Density B : it means the picks $18 / \mathrm{cmm}$ wefts,Cotton Density C: it means the picks $15 / \mathrm{cmm}$ wefts,.

***S. Number (serial number of sample ) \& loop Status : it means the level of piles. \& loop Status : (Height ) the height level of pile or loop length : (Medium ) the Medium level of pile or loop length., : (Low ) the Low level of pile or loop length.

** Repeat Length $(\mathrm{mm})$. *The fabrics wear made from weft yarns produced at twist factor 3.8 for weft with We consider initially the independent parameters c, W, $\mathrm{d} 1=\mathrm{d} 2=d p_{i}, p_{2}, p_{1}, p$ and in addition the: distance $\mathrm{t}$ as it is noticed in figure (3)D,E,F Geometrical model of Medium level of warp pile woven fabrics structure. 

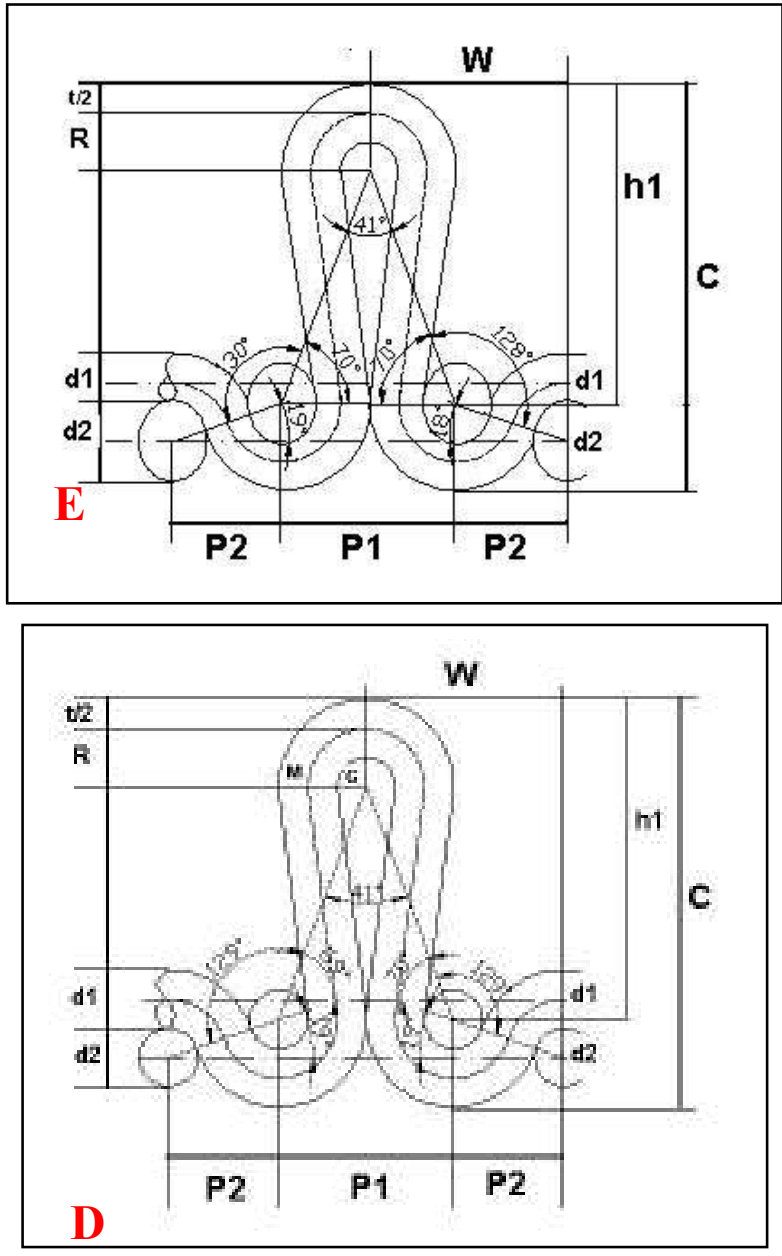

Figure (3), D,E,F. Geometrical model of Medium level of warp pile woven fabrics structure

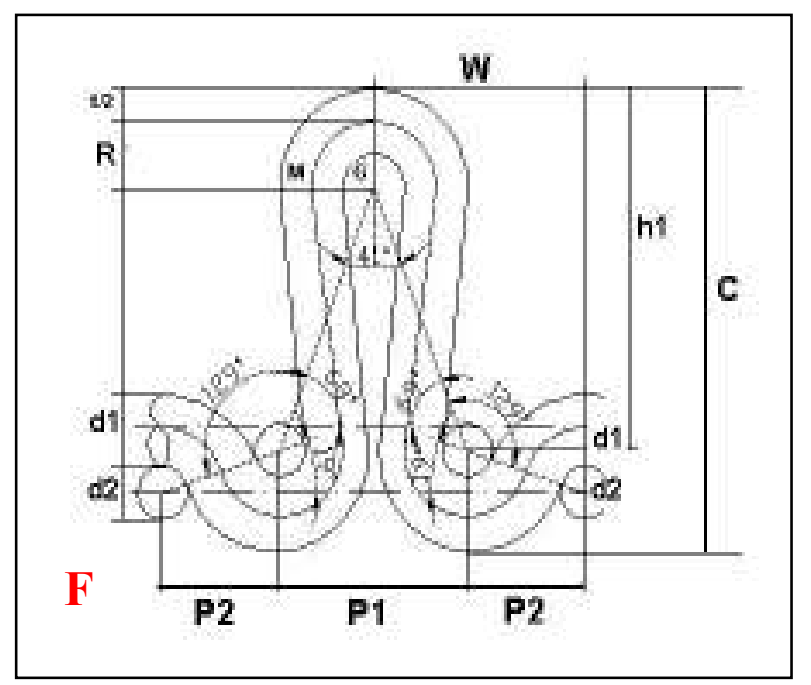


Table (3) Comparison of measured warp pile loop length.

\begin{tabular}{|c|c|c|c|c|c|c|c|c|c|c|c|}
\hline \multirow{2}{*}{ 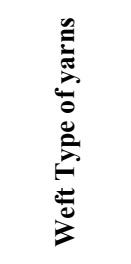 } & \multirow{2}{*}{ 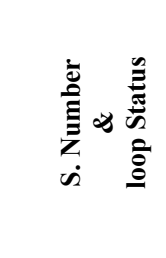 } & \multirow{2}{*}{ 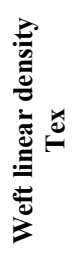 } & \multirow{2}{*}{ 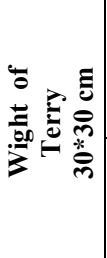 } & $\sigma \sum_{0}^{ \pm}$ & \multicolumn{3}{|c|}{ : } & \multirow{2}{*}{ 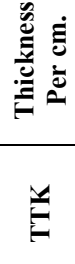 } & \multirow{2}{*}{ 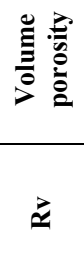 } & \multirow{2}{*}{ 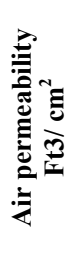 } & \multirow{2}{*}{ 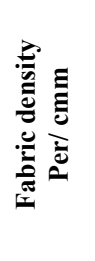 } \\
\hline & & & & $\approx$ & 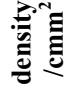 & 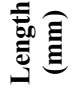 & $a$ & & & & \\
\hline $\begin{array}{c}\text { Cotton } \\
\text { Density A }\end{array}$ & 21-Medium & 37.5 & 29.83 & 0.0176 & 37.5 & 0.95 & 0.134 & 3.65 & 11.06 & 30.9 & $\begin{array}{c}22 X \\
21\end{array}$ \\
\hline $\begin{array}{c}\text { Cotton } \\
\text { Density B }\end{array}$ & 2- Medium & 37.5 & 24.62 & 0.0176 & 32.5 & 0.78 & 0.134 & 3.9 & 18.5 & 31.0 & $22 \times 18$ \\
\hline $\begin{array}{c}\text { Cotton } \\
\text { Density C }\end{array}$ & 6- Medium & 37.5 & 23.91 & 0.0176 & 30 & 0.85 & 0.134 & 3.7 & 18.38 & 31.2 & $\begin{array}{c}22 X \\
15 \\
\end{array}$ \\
\hline $\begin{array}{c}\text { Viscose } \\
\text { Density A }\end{array}$ & 11- Medium & 40 & 25.81 & 0.01847 & 37.5 & 0.68 & 0.155 & 3.4 & 13.2 & 31.2 & $22 \times 21$ \\
\hline $\begin{array}{c}\text { Viscose } \\
\text { Density B }\end{array}$ & 1- Medium & 40 & 25.03 & 0.01847 & 32.5 & 0.78 & 0.155 & 3.95 & 19.9 & 30.9 & $22 \times 18$ \\
\hline $\begin{array}{c}\text { Viscose } \\
\text { Density C }\end{array}$ & 5- Medium & 40 & 24.25 & 0.01847 & 30 & 0.85 & 0.155 & 3.55 & 21.56 & 31.2 & $22 \times 15$ \\
\hline $\begin{array}{c}\text { blended } \\
\text { Density A }\end{array}$ & 9- Medium & 25 & 24.04 & 0.0152 & 37.5 & 0.85 & 0.142 & 3.6 & 15.91 & 30.9 & $22 \times 21$ \\
\hline $\begin{array}{c}\text { blended } \\
\text { Density B }\end{array}$ & 3- Medium & 25 & 23.52 & 0.0152 & 32.5 & 0.78 & 0.142 & 3.9 & 13.08 & 30.9 & $22 \times 18$ \\
\hline $\begin{array}{c}\text { blended } \\
\text { Density C }\end{array}$ & 8- Medium & 25 & 22.99 & 0.0152 & 30 & 0.85 & 0.142 & 3.7 & 12.91 & 31 & $22 \times 15$ \\
\hline $\begin{array}{l}\text { polyester } \\
\text { Density A }\end{array}$ & 12-Medium & 17 & 23.81 & 0.0143 & 37.5 & 0.68 & 0.138 & 4.6 & 9.24 & 31.1 & $22 \times 21$ \\
\hline Density B & 4- Medium & 17 & 23.25 & 0.0143 & 32.5 & 0.78 & 0.138 & 4.55 & 8.73 & 31.0 & $22 \times 18$ \\
\hline Density C & 7-Medium & 17 & 23.17 & 0.0143 & 30 & 0.85 & 0.138 & 3.8 & 10.11 & 31.0 & $22 \times 15$ \\
\hline
\end{tabular}

*Where:dPI=diameter of warp piles,cross, section section:dPI $=0.02038 \mathrm{~cm}$.: $\mathrm{dg}=$ diameter of warp ground cross section. $\mathrm{dg}=0.02038 \mathrm{~cm}$. We consider initially the independent parametersc,

$\mathrm{W}, \mathrm{d} 1=\mathrm{d} 2=d p_{i}, p_{2}, p_{1}, p$ and in addition the:distance $\mathrm{t}$ as it is noticed in figure (4)G,H,K Geometrical model of higher level of warp pile woven fabrics structure. 

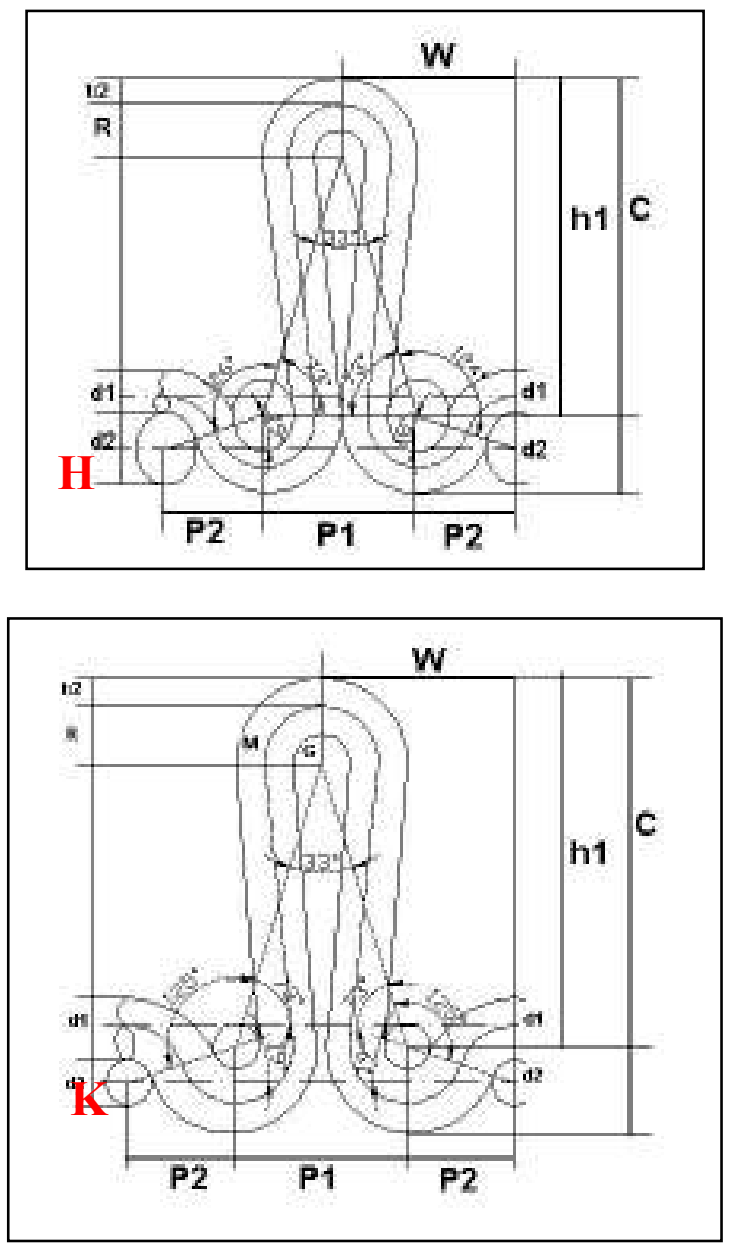

Figure (4) G,H,K.Geometrical model of higher level of warp pile woven fabrics structure.

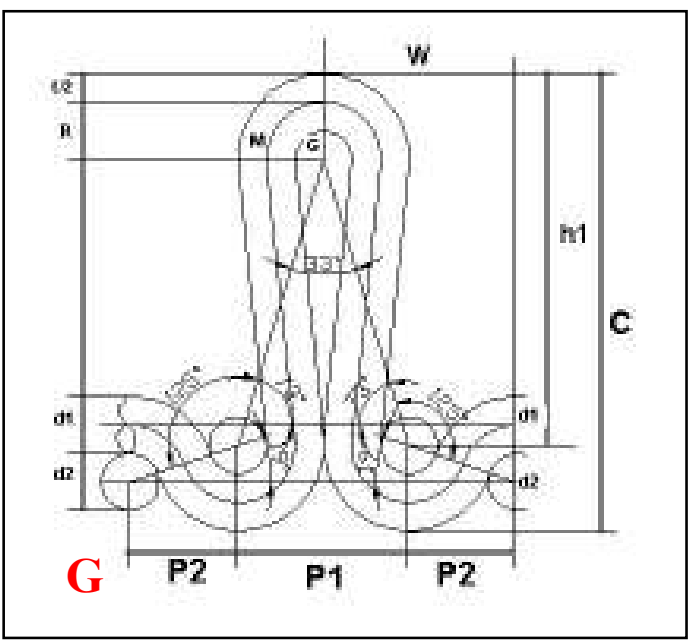


Table (4) Comparison of measured warp pile loop ength.

\begin{tabular}{|c|c|c|c|c|c|c|c|c|c|c|c|}
\hline \multirow{2}{*}{ 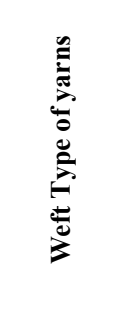 } & \multirow{2}{*}{ 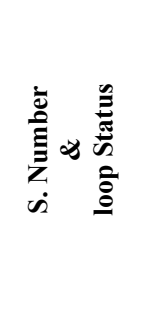 } & \multirow{2}{*}{ 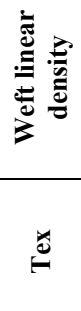 } & \multirow{2}{*}{ 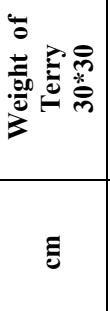 } & \multirow{2}{*}{$\begin{array}{l}=\frac{5}{0} \\
\approx\end{array}$} & \multicolumn{3}{|c|}{ 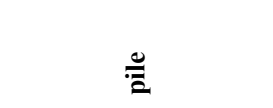 } & \multirow{2}{*}{ 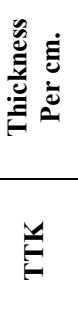 } & \multirow{2}{*}{ 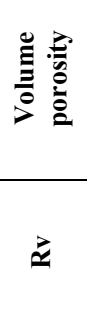 } & \multirow{2}{*}{$\begin{array}{l}=\frac{3}{0} \\
\frac{0}{0} \\
\stackrel{0}{0}\end{array}$} & \multirow{2}{*}{ 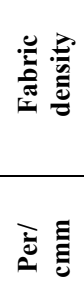 } \\
\hline & & & & & 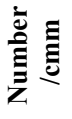 & 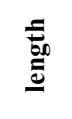 & $a$ & & & & \\
\hline $\begin{array}{c}\text { Cotton } \\
\text { Densitv A }\end{array}$ & 24- Height & 37.5 & 32.03 & 0.0176 & 37.5 & 0.95 & 0.134 & 5.5 & 10.66 & 31.3 & $22 \times 21$ \\
\hline $\begin{array}{c}\text { Cotton } \\
\text { Density B }\end{array}$ & 14- Height & 37.5 & 31.3 & 0.0176 & 32.5 & 1.1 & 0.134 & 5.0 & 12.74 & 31.3 & $22 \times 18$ \\
\hline $\begin{array}{c}\text { Cotton } \\
\text { Density C }\end{array}$ & 19- Height & 37.5 & 30.60 & 0.0176 & 30 & 1.19 & 0.134 & 4.85 & 10.91 & 31.8 & $22 \times 15$ \\
\hline $\begin{array}{c}\text { Viscose } \\
\text { Density A }\end{array}$ & 23- Height & 40 & 32.51 & 0.0184 & 37.5 & 0.95 & 0.155 & 5.2 & 12.52 & 31.2 & $22 \times 21$ \\
\hline $\begin{array}{c}\text { Viscose } \\
\text { Density B }\end{array}$ & 13- Height & 40 & 31.73 & 0.01847 & 32.5 & 1.1 & 0.155 & 4.95 & 12.45 & 31.2 & $22 \times 18$ \\
\hline $\begin{array}{c}\text { Viscose } \\
\text { Density C }\end{array}$ & 18-Heigh t & 40 & 30.95 & 0.01847 & 30 & 1.19 & 0.155 & 4.9 & 11.67 & 31.5 & $22 \times 15$ \\
\hline $\begin{array}{c}\text { blended } \\
\text { Density A }\end{array}$ & 22- Height & 25 & 30.74 & 0.0152 & 37.5 & 0.95 & 0.142 & 5.0 & 8.67 & 31.6 & $22 \times 21$ \\
\hline $\begin{array}{c}\text { blended } \\
\text { Density B }\end{array}$ & 16- Height & 25 & 30.21 & 0.0152 & 32.5 & 1.1 & 0.142 & 4.7 & 9.09 & 31.5 & $22 \times 18$ \\
\hline $\begin{array}{l}\text { blended } \\
\text { Density C }\end{array}$ & 18- Height & 25 & 30.95 & 0.0152 & 30 & 1.19 & 0.142 & 4.9 & 11.67 & 31.5 & $22 \times 15$ \\
\hline $\begin{array}{l}\text { polyester } \\
\text { Density A }\end{array}$ & 20- Height & 17 & 29.25 & 0.0143 & 30 & 1.19 & 0.138 & 4.8 & 6.77 & 31.8 & $22 \times 21$ \\
\hline Density B & 15- Height & 17 & 29.85 & 0.0143 & 32.5 & 1.1 & 0.138 & 5.6 & 5.88 & 31.4 & $22 \times 18$ \\
\hline Density C & 20- Height & 17 & 29.24 & 0.0143 & 30 & 1.19 & 0.138 & 4.8 & 6.77 & 31.8 & $22 \times 15$ \\
\hline
\end{tabular}

*The fabrics wear made from weft yarns produced at twist factor 3.8 for weft with $(Z)$ direction.Where: $\mathrm{dPI}=$ diameter of warp piles cross section.: $\mathrm{dPI}=0.02038 \mathrm{~cm} . \mathrm{dg}=$ diameter of warp ground cross section. $\mathrm{dg}=0.02038 \mathrm{~cm}$.

$$
\ell p i=\pi \Delta r-\Omega r \quad(26)
$$

Where $\ell$ is loop length [mm], $\Omega r$ is loop width [mm], $\Delta r$ is loop height [mm]

$$
\begin{aligned}
& p_{1}=2 d p_{i}+d_{2}(27) \\
& p=4 d p_{i}+3 d_{2}(28)
\end{aligned}
$$

\subsection{Calculation of terry loop length $(L)$}

Due to the symmetry of the unit cell the length of the warp pile loop is received by the equation 12. Yarn crimp ratio cross-section change is not neglected it may be assumed, that greater angel of contact will be connected with more important change of yarn cross-section from circular into approximately elliptical. 


$$
\begin{aligned}
& c_{P i}=\frac{\pi\left(d_{2}+d_{2}\right)}{180 \sqrt{d_{2}^{2}+2 d_{1} d_{2}}} \\
& +(\pi \Delta r-\Omega r) \cos -1 \frac{d_{1}}{d_{1}+d_{2}}-1
\end{aligned}
$$

Due to the symmetry of the unit cell the length of the pile is received by the equation (26).

\subsection{EVALUATION OF THE GEOMETRICAL MODEL}

For detection of geometric characteristics of structure of the warp pile fabric of cotton, polyester, viscose rayon, blended (polyester/cotton), for weft and the warp of cotton (the same fabric as used for measuring of bending rigidity and hysteresis, under bending load, the method of direct research of inner structure of fabric was used. It was done with help of analysis of soft of fabric samples, introduced in the individual parameters of bent plane weave fabric were measured

The evaluation of the geometrical model is based initially on the comparison of the experimentally defined warp pile loop length of a given fabric to the respective calculated by the geometrical model for the same main parameters $(c, w, D)$. The main structural parameters of a fabric can be defined after a microscopic observation and the warp pile loop length can be measured using the crimp tester. Table 2 contains the main parameters, the measured warp pile loop lengths and the geometrically calculated warp pile loop lengths for eight randomly selected fabrics. The error between the calculated warp pile loop length and the measured one is considered as the indication of the accuracy of the geometrical model.

\begin{tabular}{|c|c|c|c|c|c|c|c|c|}
\hline 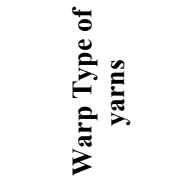 & 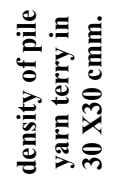 & $\sum_{i}^{ \pm}$ & & 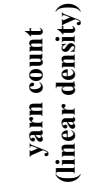 & 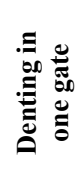 & 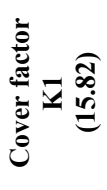 & ○ & 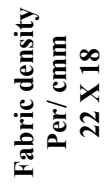 \\
\hline Pile yarns & 336 & \multirow[t]{2}{*}{ Plain } & 3.8 & 50Tex & 1 & 14.52 & 0.02038 & 11 \\
\hline Ground yarns & 336 & & 2.5 & 50 Tex & 1 & 16.82 & 0.02038 & 11 \\
\hline
\end{tabular}

Table 4: the parameters of warp in towel fabrics:

*The fabrics wear made from weft yarns produced at twist factor 3.8 for weft with $(\mathrm{Z})$ direction. Where: $\mathrm{dPI}=$ diameter of warp piles cross section.: $\mathrm{dPI}=$ $0.02038 \mathrm{~cm} .: \mathrm{dg}=$ diameter of warp ground cross section. $\mathrm{dg}=0.02038 \mathrm{~cm}$. 


\subsection{STRUCTURE SIMULATION OF A WARP PILE WOVEN FABRICS}

Due to the structural symmetry of a warp pile woven fabrics and to the load conditions of the tensile test, the unit cell is considered as the one quarter of the warp pile loop (Figure 2,3,4).The yarns are represented as homogenous cylinders of constant diameter, with initially restricted contact area between them. We consider orthotropic structure properties of the yarn with three level of pile modules, one for the yarn axis direction and one for the yarn radius direction. The boundary conditions that are applied for the simulation of the level of pile test of allow deformation of the unit cell considered as being positioned in the center of the specimen. simulation of the Structure test of a of a warp pile woven fabrics as it is executed at The main purpose of this pile unit is the creation of a model of the a warp pile woven fabrics structure via AutoCAD software programming and use of the 3-dimensional visualization of the structure and the simulation of the loop testing of Pile Woven Fabrics. This method supports the better understanding of the deformation process of the yarns Pile due to the applied draw in the fabrics. By comparing the three levels curves resulting from the simulation of the experimental ones the accuracy of the geometrical characteristics used for the modeling is estimated. The deformation process of the of a warp pile woven fabrics structure fabrics is characterized by the superposition of three deformation modes(height level, medium, low) with three density of weft $(15,18,21)$, which correspond in the bending. These three regions cannot be absolutely distinguished and are also accompanied by the yarn slippage and the compressional deformation of the yarns at the link points of the warp pile loops. Especially at low density conditions, that is the region of the main interest, the dominating mechanism of deformation is the change of the warp pile loop shape due to the bending of the yarns. Under these conditions the shaped arcs of the loop have a significant influence in the deformation process. since the mechanical loading of the yarns imposes increase of the contact area with essential local deformations. The satisfactorily fitting of the theoretical curves to the experimental ones ensures among others the accuracy of the geometrical characteristics that are used for the modelling. Correlation between a structural parameters and air permeability experimental values For all fabrics the air permeability values were measured. and relationships between experimental porosity and air permeability values and structural characteristics of woven fabrics(determined according to method).were used for measuring of air permeability of warp pile woven fabric. The all parameters of warp pile structure mentioned above were calculated and for all warp pile fabrics porosity and air permeability was measured. Apparently from the tablel and figure 5 that the specific volume of porosity and air permeability are shown constructional parameters of used fabrics(type of 
wefts)and levels of loop. the specific volume is significantly influenced by behavior of the filling spaces in between structural characteristics values of porosity and air permeability in low level of piles and their deviations from experimental warp pile woven fabrics air permeability values. $t$ is evident that in the cases of relatively "opened" fabrics(area covering value is relatively low)the suggested method gives relatively good results. In the cases very dense fabrics the results(predicated values of warp pile woven fabrics of porosity and air permeability) are not so accurate.

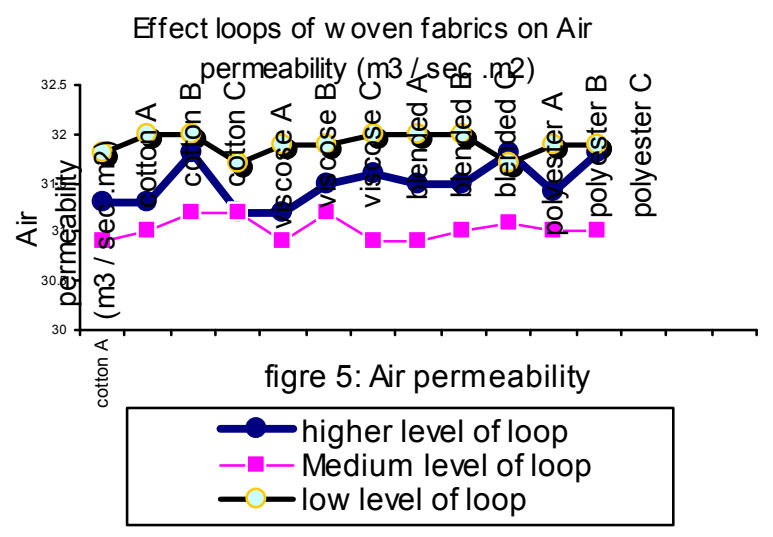

Apparently from the figure 6 that the specific volume of porosity the low level of piles and low density $15 \mathrm{weft} / \mathrm{cmm}$ are highest value of porosity than the medium(18)wefts and highest (21)weft, this work foundation and the suggested process makes possible Mathematical of pile woven fabrics to prediction of suitable sett of warp and weft(18),porosity and air permeability value of pile warp woven fabrics(cotton), which are characterised by their constructional parameters as are sett of warp and weft yarns, diameters or fineness of warp and weft yarns and by the plain of weave. On the base of the area covering value is chosen suitable model for description of woven fabric structure. 


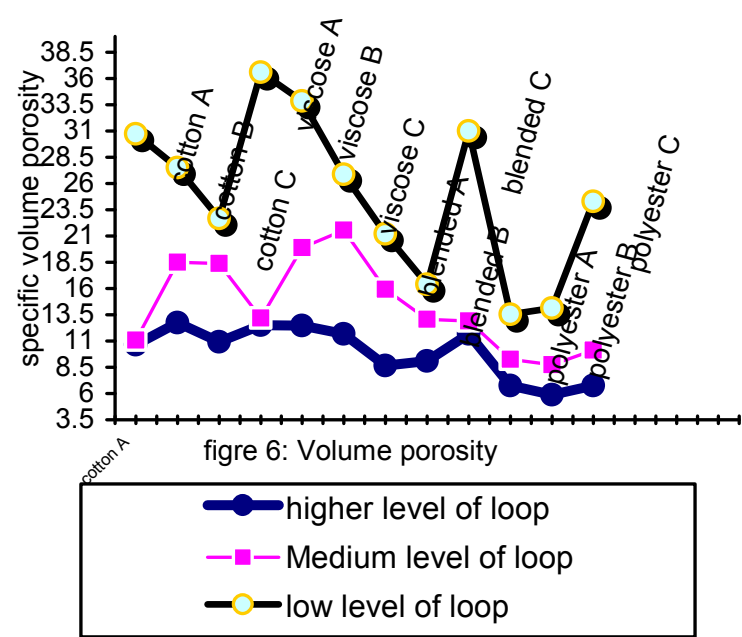

Apparently from the figure:7 that the specific volume of the thickness of highest level of loop are highest value than the medium and lower level and even used maximum density of weft, The realistic diagram based on a better approach of geometry and material properties will be created in order to investigate the numerical analysis performance of the properties of warp pile woven fabrics.to determine the weavability limit and suitable as a function of warp pile weave design and yarn diameters, and to give an idea about the maximum crimp ratio of weft, warp pile weave and cover ratio of fabrics, the lower value of weavability limit and suitable are more achievable than the higher value especially on modern sand faster weaving machines rather than multi-phase weaving machine. This research is focused on cloth of pile warp woven fabrics of a cotton type. Two variants of so-called cumulative parameter of a woven fabric structure are defined and they are applied on the set of woven fabrics. A correlation between calculated values of structural parameters and experimental air permeability values was evaluated. A structure of textile materials is very complicated and very varied. Therefore it is reasonable to use various models of a textile structure for the various groups of the textiles. The group of the textiles can be characteristic for example by some structural parameter(s). For this type of structure, a cotton, blended, viscose rayon, polyester as wefts in pile woven fabric of unit weight(Terry $30 * 30 \mathrm{~cm}) 15.9$ to 34.43 grams and thickness 2.45 to $5.5 \mathrm{~mm}$ is used two face of piles. This fabric is used in all samples so that the effects of the variables of the middle piles and density can be observed. Staple filaments. 


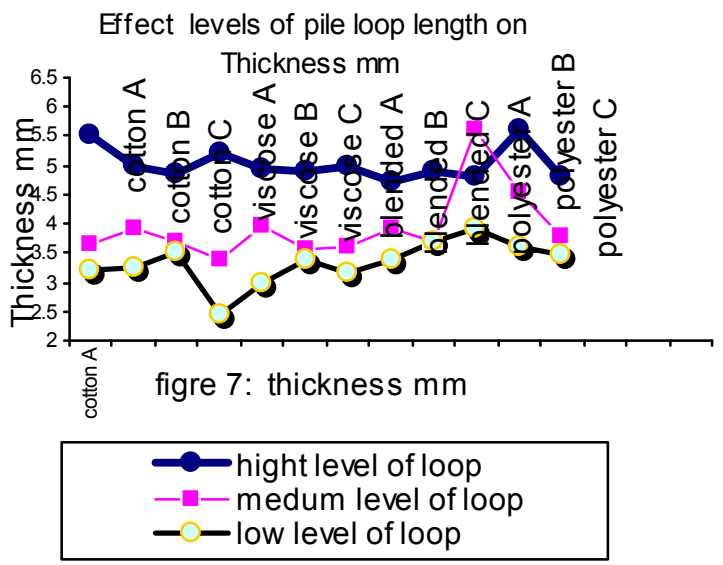

\section{Wiks-up liquid through piles}

Apparently from the figure: 8 that the specific volume of the Wiks-up in lower level of piles are highest value than the medium and higher level which used cotton and even the cotton maximum density of weft,in addition to the viscose rayon are maximum holding water behavior is higher than the pure cotton maximum holding water. This behavior indicates that the filling spaces in between fiber-to-fiber and yarn-to-yarn in the fabric, construction is decreasing by water filling up. Obviously, the specific volume is significantly influenced by the water content. The second level of pile, which wicks liquid through the pile plane with minimum wicking-up in the pile warp of the fabric, is designed as a tree-levels structure. The top and bottom piles are designed by three different density $(15,18,21)$ of weft in fabrics. These three levels of density are used as substrates in flocking. On these substrates, fibers are flocked to produce channels of pile perpendicular to the surface of the fabric, enhancing the flow in the vertical direction. These channels of pile are designed to promote the flow through the plane of the fabric, thus, minimizing the radial flow in the plane of the fabric. Two faced of pile layers are placed on top of each other with the flocked fibers facing each other. The flocking density and the stable of the fibers are varied to observe the effects of these variables in this structure. For this type of structure, the fabric used for the substrates is a woven structures of pile fabric with straight continuous wefts. These samples are tested to observe how much of the liquid dropped is transferred to the bottom piles by measuring the distance the liquid travels in the top and bottom piles. The results of these tests will be used to model wicking in these structures. 
Relationship between levels of pile loop

and Ability to absorb $\mathrm{cm}$

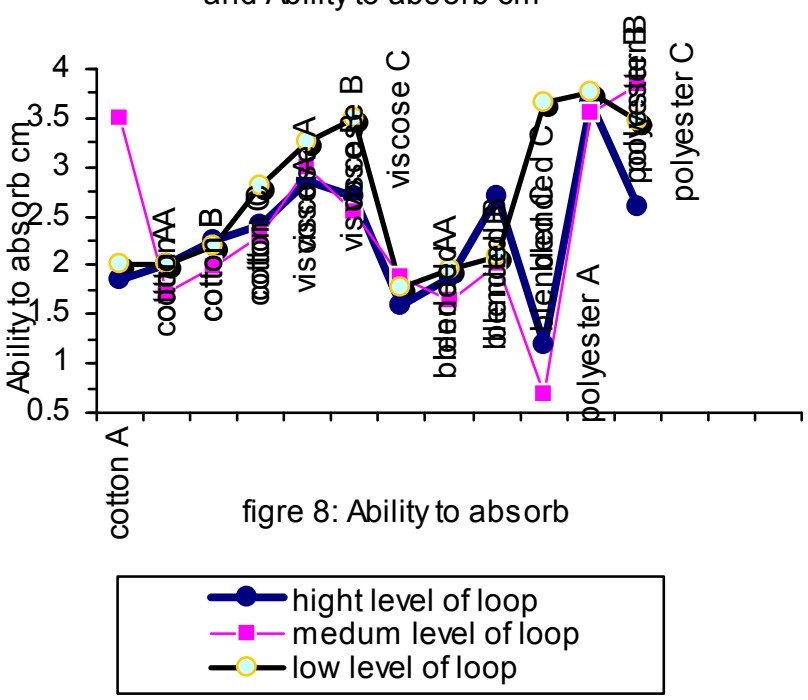

Apparently from the figure: 9 that the specific volume of loop length of the higher level of pile are highest value than the medium and lower levels, This behavior indicates that the filling density and interlacing Obviously, the specific volume is significantly influenced by loop length. For the second level of piles, the diagram will be setup to predict the effects of the Tex count of the flock fibers and the flock density. In these diagram, it will be assumed that in fabric of higher level, the middle level, which consists of parallel-laid staple filaments, and in fabric of medium level, the middle level of pile that consists of the flocked fibers, dominate the directional permeability of the fabric structures.

Relationship betw een levels of pile loop and Length $(\mathrm{mm})$ of loop

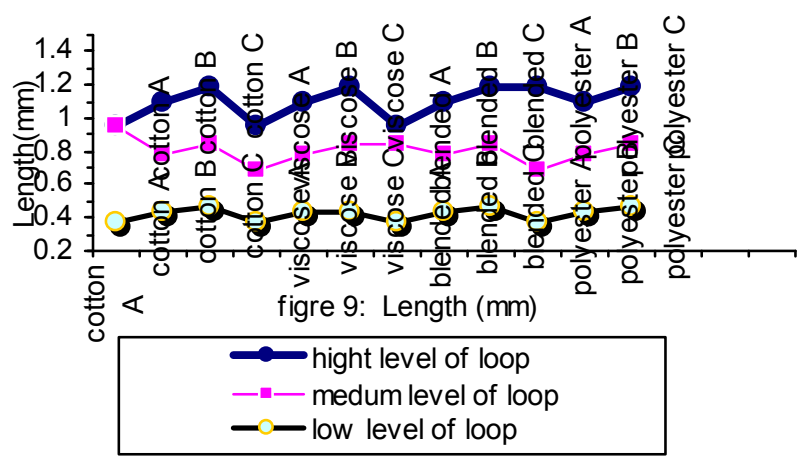




\section{CONCLUSION}

The present work has focused on the creation and the evaluation of a three-dimensional plain of a warp pile woven fabrics structure fabric geometrical model. The precision of the geometrical model has been crosschecked by using geometrical and mechanical porosity and criteria. Especially the mechanical criterion is considering the success of the geometrical model taking in account the final results analysis of the structure created. However more realistic models based on a better approach of geometry and material properties will be created in order to investigate the numerical analysis performance of the mechanical porosity and properties of a warp pile woven fabrics structure fabrics. The suggested process makes possible prediction of warp pile length woven fabrics porosity and air permeability value of warp pile woven fabrics (cotton type), which are characterised by their constructional parameters as are sett of warp and weft yarns, diameters or fineness of warp pile woven fabrics and weft yarns and by the type of weave. On the base of the area covering value is chosen suitable model for description of warp pile woven fabric structure. The porosity and air permeability value is predicted with use of chosen level and density. Two variants of cumulative parameter of a warp pile woven fabric structure were introduced.

\section{ACKNOWLEDGMENT}

The author wish's to express his appreciation to Eldelta spinning and weaving -Tanta company-Egypt, that have supported this research. Also his grateful to Prof. Dr. Hemdan Aboutaleb the Head of Textiles Engineering faculty of engineering, Mansoura University-Egypt for his confidence and support for this study.

\section{REFERENCES}

[1] A.S.T.M.Annual Book;(1981).“Standards, Textiles-Yarn-Fabric General Test Methods"-part, 22" D1777-64, ASTM.D 737- 5030." .

[2] Backer,S.(1951).The relationship between the Structural Geometry of a Textile Fabric and Its Physical Properties,Part IV:Interstice Geometry and Air Permeability. Textile Research Journal,21, 1951.

[3] Chamberlain J.(1926).Hosiery yarns and fabrics. City of Leicester College of technology. Leicester, UK, Vol.II, p.107.

[4] Ebraheem. H.A.(1997)Maximum sett of Woven fabrics.,Mansura Engineering Journal(MEJ), faculty of Engineering, Mansura University , Vol, 22,No.3.September. 
[5] Elnashar.E.A.(May 2005)"Volume Porosity and Permeability in Warp Pile Woven Fabrics"."The VIIIth International Workshop"Physics of Fibrous Materials:Structure,Properties,Science Intensive Technologies and Materials"(SMARTEX-2005)that will take place in the Ivanovo State Textile Academy(Russia)from 30th to 31st of May, 2005.

[6] Gooijer,H.(1998). Flow resistance of Textile Marerials. Thesis UT Enschede. 1198. ISBN 90-36511240.

[7] Grosberg,P.(1955):"The medium and long term variations of a yarn I", The Journal of the Textile Institute, 1955,T301.

[8] Havrdova.M,.(2005)"Prediction of woven fabric air permeability "5 th World Textile Conference Autex 2005,27-29 June 2005, Portorož, Slovenia.

[9] Havrdová,M.(2003).Air permeability and a structure of woven fabrics. Vlákna a textil, 10(2) 86-90 (2003),1335-0617.

[10] Hearle.J.W.S.(2004). The challenge of changing from empirical craft to engineering design, International Journal of Clothing Science and Technology, Vol. 16, No 1/2, pp 141-152.

[11] Höerner,S.F.(1952).Aerodynamic Properties of Screens and Fabric. Textile Research Journal, April 1952, $274-280$.

[12] Lu,W. M.et all(1996). Fluid Flow Through basic Weaves of Monofilament Filter Cloth. Textile Research Journal, 66 (5), 311- 323.

[13] Pedersen,G.C.(1974).Fluid Flow through Monofilament Fabrics. Filtration/Separation, November/December 1974.

[14] Peirce.F.T.(1947).Geometrical principles applicable to the design of functional fabrics, Textile Research Journal, 17, 123-147.

[15] Plate,D.E., and hepworth, K.,(1973)"Beat-up forces in weaving", PartII, J.T.inst., 64, T233-T249,.

[16] Seyam,A, and El-sheikh.A., (1993)Mechanics of Woven Fabrics, Part III: critical Review of weaveability limit studies, textile research journal, 63, 371-378,.

[17] Seyam,A,and El-sheikh.A.,(July,1990) Mechanics of Woven Fabrics, Part I: theoretical investigation of Weavability limit of yarns with thickness Varition, Textile research institute, 389-404.

[18] Snowden.D.C.,(1967)construction of woven fabrics with particular reference to weaving values and sett/count/ weight calculation, textiles inst. Ind .5,137-140,

[19] Vassiliadis.S., Kallivretaki A., Gurkan P. and Provatidis Ch.(2005). Fabric Hand: An Important Quality Parameter of the Textile Fabrics. 2nd Int.Conf.on Information Technology and Quality, Greece. 


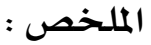

البحث المقدم نموذج لطريقة فهم سلوك تشكيل حجم عناصر تصميم أقمشة الوبرة مـن السداء

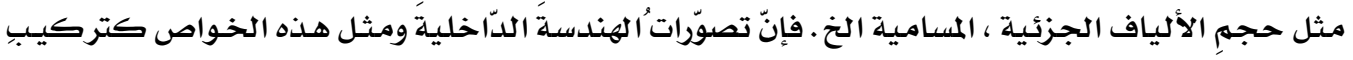

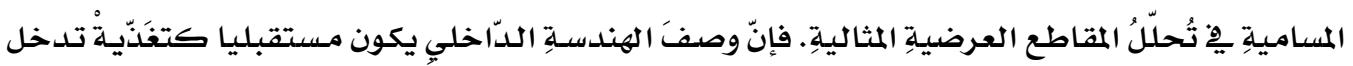

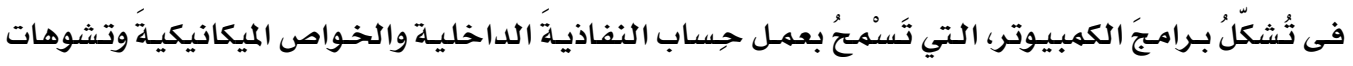

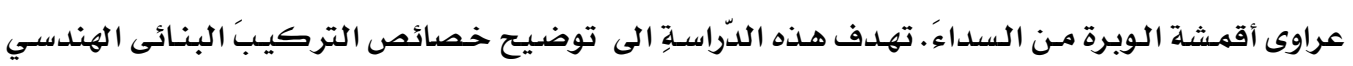

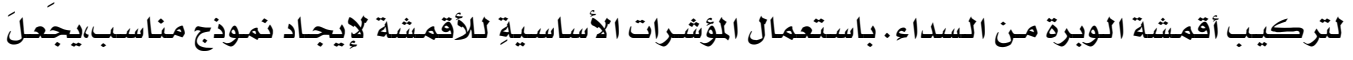

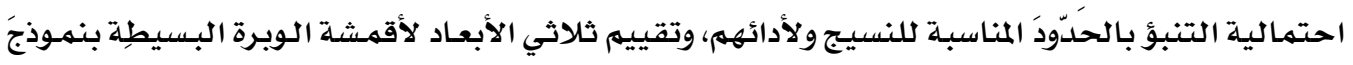

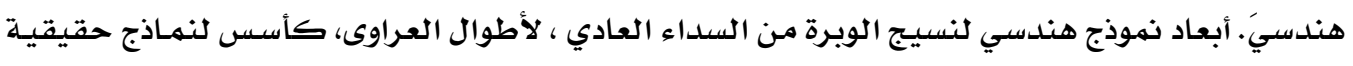

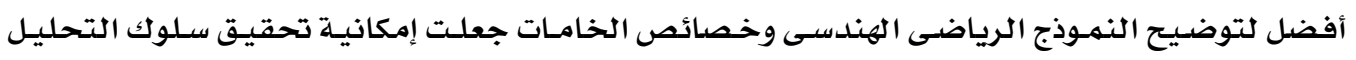

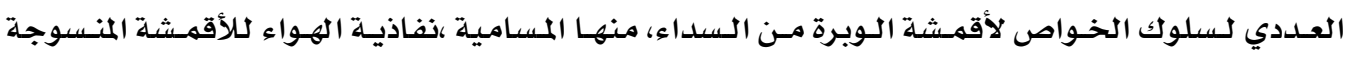

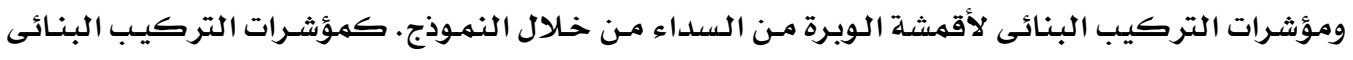

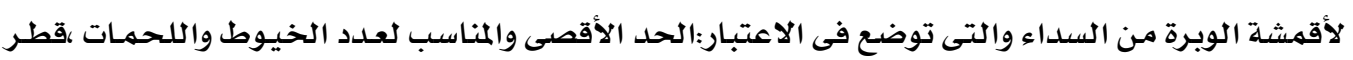

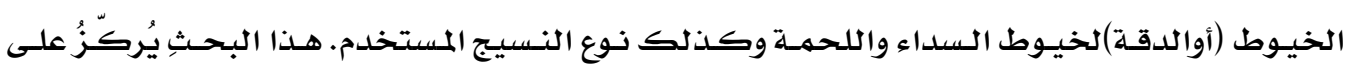

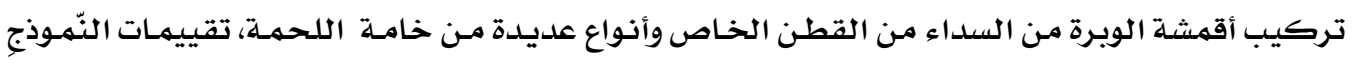

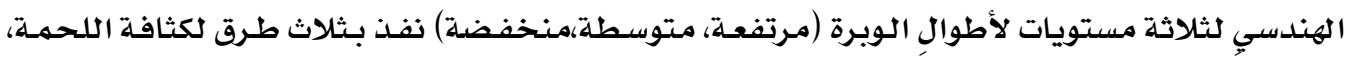

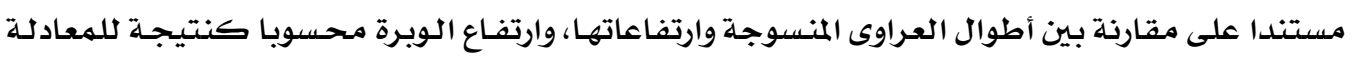

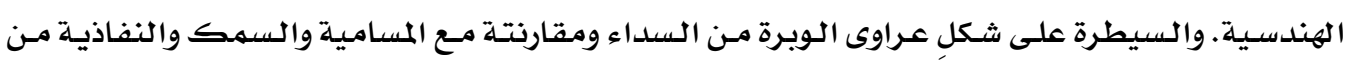

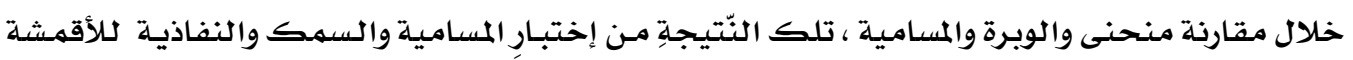

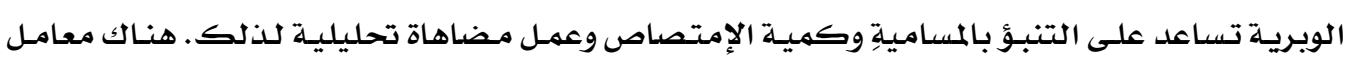

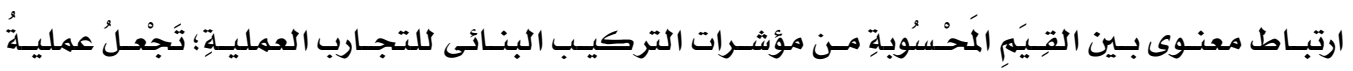

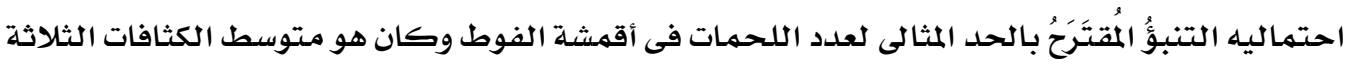

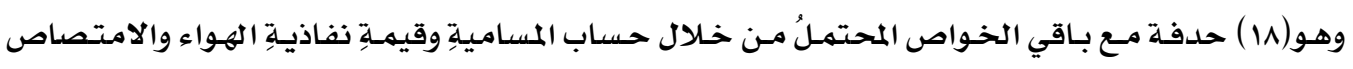

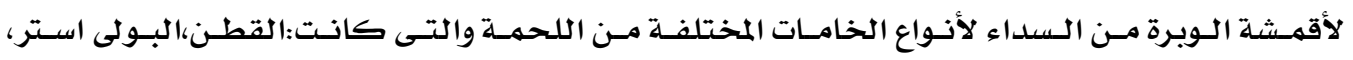

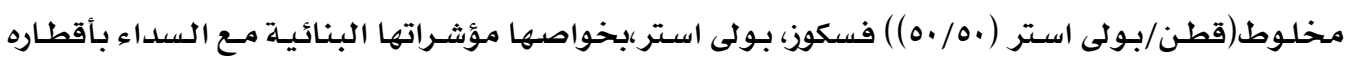

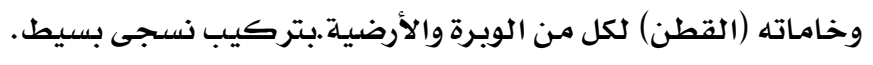

الكلمات المرشدة : قابيلة النسيج ،هندسة أقمشة الوبرة ،النفاذية ،المسامية. نموذج هندسى. 